\title{
Entre tecnicidades e ritualidades: formas contemporâneas de performatização da notícia na televisão
}

\author{
Juliana Freire Gutmann
}

Resumo: Com o objetivo de contribuir para o refinamento metodológico da análise de programas televisivos, o artigo propõe uma abordagem dos telejornais que leve em conta sua dimensão comunicacional, privilegiando a interpretação de suas formas materiais, culturais e simbólicas. Analisa as performances do repórter que virtualizam posições para o espectador, constituindo espaços de subjetividade que contrastam com o discurso normativo sobre as práticas do campo. O artigo sugere um caminho para a análise televisiva que leve em conta o diálogo entre os estudos culturais e a semiótica e, pela demonstração do trabalho empírico, identifica articulações possíveis entre marcas formais instituídas e novas formas de performatização da notícia no telejornal de rede brasileiro.

Palavras-chave: análise televisiva; performance; telejornal.

Abstract: Between technicalities and ritual practices: contemporary forms of performance in television newscasts - Seeking to contribute to the methodological refinement of the analysis of television shows, this paper proposes an approach to newscasts that considers the communication dimension and favors the interpretation of their material, cultural, and symbolic forms. This study focuses on analyzing reporters' performances that foster a virtual interaction with the viewer and generate subjective areas that contrast with the normative discourse on field practices. The article suggests a path to television analysis that considers the dialogue between cultural studies and semiotics. By presenting empirical work, it also identifies possible links between established formal marks and new forms of performance in the Brazilian television news network.

Keywords: television analysis; performance; newscast. 


\section{Constatações e propósitos}

A reconhecida importância cultural que a TV e o telejornalismo assumiram no Brasil tem demandado, ao campo da comunicação, esforço na direção do refinamento dos métodos de análise dos seus produtos e linguagens. Sobre o telejornalismo, os estudos avançam em relação, por exemplo, aos seus aspectos culturais (GOMES, 2012), narrativos (COUTINHO, 2012), às performances e constituições de presenças (FECHINE, 2008), às dinâmicas sociais que dão conta do seu processo histórico (SILVA, 2012; GOULART, SACRAMENTO, 2012), aos vínculos afetivos propostos com a audiência (HAGEN, 2008), ao papel de suas constituições discursivas nas expressões de identidades (BECKER, 2005) etc. Do ponto de vista acadêmico, essas pesquisas tem promovido importantes reflexões que reforçam o caráter cultural e comunicacional do jornalismo televisivo, considerando-o enquanto fenômeno midiático em permanente transformação. Pautado nesse pressuposto, este artigo parte de uma leitura crítica dos discursos reproduzidos sobre a prática profissional, presentes especialmente nos manuais de telejornalismo, nos quais é possível apreender uma dimensão institucionalizada desse fazer, que evita reflexão sobre suas transformações e modos de ser (LEAL, 2012). Impera uma espécie de dissonância entre continuidades da ordem do discurso e descontinuidades de ordem cultural.

Tomando um fato empírico para exemplificar o argumento, permito-me inverter a lógica de demonstração deste estudo analítico para antecipar uma constatação. Apesar de o discurso normativo sobre o telejornalismo ainda indicar que repórteres e apresentadores devem agir como sujeitos isentos que não se confundem com a notícia e nem com um personagem (BARBEIRO \& LIMA, 2002), nos programas, atuam sujeitos sociais que se implicam nos relatos e fazem do seu corpo lugar de personificação da notícia. E se o telejornal brasileiro foi concebido historicamente pelo esforço de se distanciar da herança radiofônica, marcada pela emotividade, em direção a um estilo sóbrio e distanciado do público, o que supostamente lhe garantiria autoridade e credibilidade, hoje a disputa por esses mesmos valores também se faz por estratégias de proximidade com o espectador. Dentre as questões que essa constatação põe em jogo, a que nos interessa, por hora, é o considerável incremento dos usos de elementos expressivos da TV (o corpo, a transmissão direta, o audiovisual etc.) responsáveis por constituir espaços de subjetividade, que ainda contrastam com o discurso normativo sobre as práticas do campo.

Motivado por esta inquietação, este artigo tem como objetivo analisar uma das dimensões materiais da TV que considero central na produção de sentido da notícia, as performances dos repórteres, de modo a interpretá-las como forma cultural do telejornal. Esse esforço empírico sintetiza um segundo objetivo: sugerir uma perspectiva metodológica para análise televisiva, com ênfase no seu aspecto comunicacional, inspirada numa apropriação do Mapa das Mediações de Jesus Martín-Barbero em articulação com a noção pragmática de contexto comunicativo. 
Ganha relevo a intenção de desvendar o caráter comunicacional dos telejornais a partir da análise das performances dos repórteres durante a passagem (momento da sua aparição nas reportagens) e de como tais performances virtualizam posições para o espectador. Através da análise, busca-se demonstrar como formas historicamente construídas são sustentadas, rompidas e reconfiguradas, impondo-se como estratégias de comunicabilidade desse gênero televisivo na contemporaneidade.

\section{Senhas metodológicas: sobre tecnicidades e ritualidades}

Pautada num claro interesse pela abordagem do telejornalismo na perspectiva do processo comunicativo que eles engendram enquanto fenômeno da cultura, a abordagem teórico-metodológica proposta investe na produtividade do diálogo entre os estudos culturais e a semiótica. O trabalho concebe o telejornalismo enquanto forma cultural e adota o conceito de contexto comunicativo, numa perspectiva pragmática, como lugar central de observação da produção de sentido dos telejornais.

O primeiro deslocamento teórico-metodológico que se pretende aponta para uma abordagem que não se restrinja às técnicas e práticas produtivas do jornalismo, mas leva em conta articulações entre estratégias de produção e reconhecimento da notícia e os produtos que materializam discursos sociais. O telejornalismo é tomado como instância mediadora, nos termos de Jesus Martín-Barbero, como lugar de articulação entre cultura, comunicação e política que põe em diálogo lógicas de produção e de consumo, formas industriais e matrizes culturais (GOMES, 2011).

Tal proposta metodológica é figurada pelo Mapa das Mediações (Fig. 1), pensado por Martín-Barbero (2008) como forma de operacionalizar a análise dos fenômenos sociais, que relacionam comunicação, cultura e política, considerando a articulação entre produtores, meios, mensagens, cultura e receptores. O esquema move-se sobre dois eixos, um diacrônico entre matrizes culturais e formatos industriais, e um sincrônico entre lógicas de produção e competências de recepção. Essas quatro dimensões do processo comunicativo são articuladas pelas mediações de institucionalidade, socialidade, tecnicidade e ritualidade.

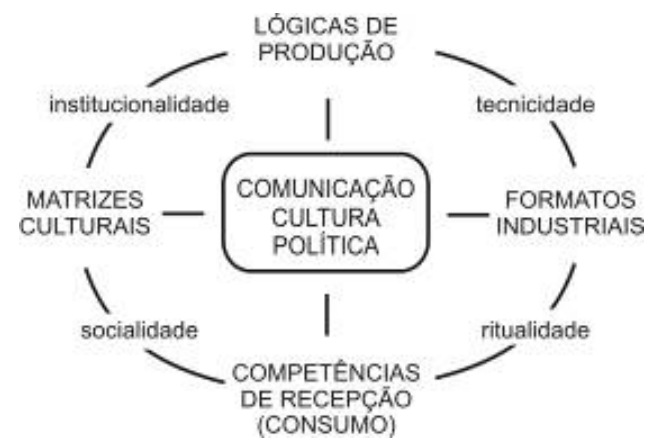

Fig.1. Reprodução do Mapa das Mediações (MARTíN-BARBERO, 2008, p.16) 
Partindo desse pressuposto geral representado pelo Mapa, o investimento deste artigo recai sobre o modo como determinado formato industrial (o telejornal) aciona elementos da linguagem televisiva, especificamente o corpo do repórter, para a constituição de estratégias de comunicabilidade. A apropriação do Mapa, portanto, é feita no marco dos formatos industriais e privilegia articulações do nível sincrônico entre estratégias de produção e competências de consumo, instâncias que se ligam aos formatos através das mediações de tecnicidade e ritualidade.

O sentido de tecnicidade não se relaciona à ideia de aparato tecnológico, mas à competência na linguagem (MARTíN-BARBERO, 2004, p.237). São as materialidades no discurso que remetem à constituição de gramáticas que dão origem aos formatos midiáticos, recuperando o original sentido do termo grego techné, que remetia ao saber fazer, à habilidade de expressar através de formas materiais, destreza que se atualiza com base nos modos de lidar com a linguagem. A tecnicidade não se refere aos instrumentos, mas aos saberes, à constituição de práticas discursivas, aos modos de percepção social.

Já a mediação da ritualidade se relaciona àquilo que configura os nexos simbólicos, tornando possível a constituição de sentidos (MARTíN-BARBERO, 2004, p.323). Não por acaso relaciona os formatos à recepção, uma vez que permite observar trajetórias de leituras, apropriações dos meios convocadas pelos produtos, regulando interações entre espaços e tempos da vida cotidiana e espaços e tempos midiáticos (MARTíN-BARBERO, 2008, p.19). Não se trata do processo de dar significação às mensagens, refere-se aos sentidos produzidos na relação com os interlocutores num movimento de dar conta dos modos de interação e contextos acionados pelos textos, perspectiva que alude a um olhar pragmático.

Tomando o telejornal como objeto de estudo, é possível concebê-lo como um formato industrial cujas tecnicidades são as formas materiais e simbólicas de lidar com valores jornalísticos na TV (as gramáticas discursivas) e as ritualidades são os modos de constituição de um lugar de interação com o público (as gramáticas de uso). As outras duas mediações, as socialidades, pelas quais reconhecemos a experiência coletiva da vida cotidiana, e as institucionalidades, espaço de legitimação dos discursos sociais, também são acionadas na análise deste artigo, ainda que de modo secundário. A interpretação de como os corpos, enquanto tecnicidade, ritualizam modos de se relacionar com a notícia prevê, por exemplo, a consideração de valores instituídos do jornalismo e suas relações com modos de vida de uma dada coletividade, seus gostos, hábitos de consumo, relações com territorialidades. O reconhecimento social de valores jornalísticos (atualidade, revelação pública, vigilância, por exemplo) e de como eles configuram representações de cotidianidade responde pela legitimação social dos programas, processo que depende da habilidade do telejornal em posicionar o público como seu interlocutor. É nesse movimento que atua o contexto comunicativo.

Concebido como lugar configurador da comunicabilidade televisiva, o contexto comunicativo compreende os enunciadores (representados pelos mediadores de um telejornal), os enunciatários (a audiência presumida que atua como interlocutora e 
também pode adquirir diversas figurativizações nos textos) e as circunstâncias espaciais e temporais construídas nos programas. Para entender o contexto comunicativo de um telejornal é preciso interpretar como o sujeito que tem voz (apresentadores, repórteres, comentaristas, editores, cinegrafistas) reconhece o outro (o espectador) e o posiciona no texto. O olhar se volta para a cena criada, para o modo como os sujeitos se apresentam e constroem posições, tempo e espaço, movimento que pressupõe reconhecimento de expectativas e competências da audiência. Pela análise do contexto, entendemos como se constroem posições e vínculos com o interlocutor.

Em termos metodológicos, o contexto comunicativo parece funcionar como um profícuo operador analítico para olhar, no interior dos produtos, o eixo sincrônico do Mapa - que articula lógicas de produção aos formatos pelas tecnicidades, e os formatos às competências de consumo pelas ritualidades - para a interpretação da situação estabelecida no interior dos programas, responsável por ambientar as enunciações. Refiro-me ao lugar de comunicabilidade televisiva que orienta a produção de sentido na TV.

\section{Repórter: performer da notícia}

Apesar de não se relacionar especificamente com o audiovisual, o conceito de performance desenvolvido por Paul Zumthor (2000) representa um legado para o estudo da dimensão televisual do jornalismo. Pela reflexão desse autor, um texto, ao ser performatizado por um corpo, incorpora marcas deste, as quais são atualizadas pelo receptor. Assim, procura-se avançar num entendimento inicial de que todo texto pressupõe um corpo performático implícito (ECO, 1986), atacando as possibilidades de experiências corporais inscritas nos textos como indicadores de leitura ${ }^{1}$. Tal pressuposto nos leva a admitir que, nos programas televisivos, performances específicas são corporificadas pelos sujeitos falantes a depender do tipo de interação proposta e que, para haver engajamento do espectador, este deve, também, reconhecer posições e lugares de atuação representados nos textos, mesmo enquanto corpos/performances virtuais.

Pensadas enquanto estratégia de presentificação, o que supõe competências do leitor, as performances podem funcionar no telejornal para materializar sentidos relacionados a valores jornalísticos, como os de atualidade, objetividade e interesse público. O acesso aos acontecimentos é dado por essas camadas de medição, conformadas por dispositivos expressivos como voz, gesto, posicionamentos de câmera, figurino, transmissão direta etc. Assim, a notícia aparece quase sempre personalizada, através de corpos que se relacionam, sucedem-se e se contrapõem, compondo o todo narrativo do programa (MACHADO, 2001). Parte dessa arquitetura de vozes, o repórter se impõe como um elemento central de autenticação dos relatos ao representar a presença simbólica da TV no local e na duração temporal do acontecimento. Ao olhar para a câmera, operação identificada

1 Ao discutir a ampliação da noção de texto literário, Zumthor (2000) põe em evidência uma dimensão de atuação em que a voz, o corpo, a presença atuam no texto e são acessados no ato de leitura - dimensão entendida enquanto performance. 
por Veron (1983) como estratégia de desficcionalização do discurso, ele nos posiciona como interlocutor primeiro da sua fala, constituindo dimensão dialógica.

As qualidades desse sujeito corporificado foram culturalmente construídas por uma lógica relacional, na qual o valor positivo estaria relacionado a uma suposta qualidade neutra. Fechine (2008) utiliza a "lógica da gradualidade" proposta por Fiorin, pela qual o atributo positivo é constituído pelo jogo relacional entre dois polos negativos (o exagero e a insuficiência), para interpretar o que seria a "justa medida" nas performances dos mediadores de telejornal. Ao pressupor uma caracterização que represente um sujeito imparcial frente ao acontecimento, investe-se na firmeza da fala (que estaria entre o ríspido/duro e o delicado/ mole) e na gestualidade moderada (entre o exagerado/espalhafatoso e o insuficiente/apagado).

Seguindo essa lógica, o modelo de atuação consagrado do repórter é caracterizado pela sobriedade da sua postura diante da câmera, distanciamento em relação à ação narrada e ao seu interlocutor, num esforço de constituir uma espécie de "não eu", figurativização de uma suposta imparcialidade do telejornal. A norma prevê para o repórter o corpo do homem civilizado, que explora pouca movimentação corporal, tem gestos comedidos e uma expressão facial séria (CAMPELO, 1996, p.92-93). Geralmente, aparece de pé em plano americano, que o coloca de modo mais distanciado do espectador e valoriza o contexto visual do fato noticiado.

Contemporaneamente, esse tipo de caracterização tem concorrido com uma segunda forma de performatizar a notícia identificada pela assumida configuração de uma persona que utiliza seu corpo como dispositivo expressivo de interpretação do enunciado. Se a regra era apresentar-se de modo "neutro" através da figura do repórter-ventríloquo que fala sobre os fatos, afirmando-se como ponto de passagem do enunciado, agora o corpo do repórter começa a ser explorado como lugar de performatização do acontecimento, fenômeno semelhante ao que Verón (1983) destacou para identificar o "apresentador moderno".

A tendência observada sobre a personalização dos apresentadores dos telejornais brasileiros, a partir do final da década de 1990, quando começam a se projetar enquanto "eu" no discurso (MACHADO, 2001; FECHINE, 2008; HAGEN, 2008), vem sendo incorporada pelo repórter, que passa a se valer de um sistema gestual complexo do corpo midiatizado. Ele interpreta corporalmente o dito, explora expressões faciais, gestualidades, proximidades e distanciamentos da tela, apresentando-se como sujeito implicado na ação narrada, o que indica a construção de um outro lugar para o espectador.

\section{Subjetivações do telejornal}

Com base na análise das performances acionadas por repórteres em matérias exibidas por telejornais de rede brasileiros ${ }^{2}$, foi possível destacar, pelo menos, duas distintas posições

2 A análise apresentada neste artigo se origina de uma pesquisa mais ampla (GUTMANN, 2012) que teve como corpus 15 telejornais de rede brasileiros exibidos em sinal aberto. São eles: Bom dia Brasil (Globo), Primeiro Jornal (Band), Fala Brasil (Record), Jornal do SBT Manhã (SBT), Repórter Brasil/ edição matutina (TV Brasil), Jornal Hoje (Globo), Jornal Nacional (Globo), Jornal da Band (Band), Jornal da Record (Record), SBT Brasil (SBT), Rede TV News (Rede TV), Repórter Brasil/ edição noturna (TV Brasil), Jornal da Globo (Globo), Jornal da Noite (Band) e Jornal do SBT (SBT). Entre 2008 e 2010, foram colhidas, de modo randômico, três amostras de cada 
construídas para o espectador, sujeito testemunha e sujeito cumplice, que se relacionam a distintos tipos de performance do repórter televisivo. É importante ressaltar que esses lugares construídos para os sujeitos comunicativos não são classificações, mas indicações de uma postura majoritária. Isso significa que, numa mesma reportagem, pode haver gradações de testemunho e cumplicidade, assim como outras posições acionadas pelos repórteres e demais corpos presentes em uma matéria, como as fontes de informação.

Além disso, reconhece-se que as duas posições destacadas se relacionam com o sentido de testemunha, ou seja, representam o lugar construído para aquele que está interessado em saber sobre as coisas do mundo e, para isto, dispõe-se a testemunhar falas, ações e discursos. Ainda assim, optou-se por destacar um tipo específico de posição construída para o interlocutor, denominada de sujeito testemunha, por esta indicar uma forma mais explícita de posicionar o espectador como alguém que assiste ao que é revelado, mas sem a demanda de uma adesão mais próxima.

Nesse tipo de posicionamento, presente na maior parte das sequencias narrativas de um telejornal, o repórter olha para o público, mas este não é explicitamente convocado para se engajar na situação vivida in loco pelo sujeito de fala. Ao contrário, é colocado como um "outro" (para quem se fala) distanciado, que não é incluído na história relatada, ainda que a testemunhe. Como exemplo, veja-se a passagem da reportagem do Jornal do SBT Manhã sobre o problema das creches clandestinas no Brasil.

Quem precisa e pode paga, mas, mesmo assim, com dificuldade. Aqui, $70 \%$ dos alunos têm renda familiar de até três salários mínimos. A mensalidade no período integral representa mais de $30 \%$ de todo o orçamento doméstico da maioria. Crédito: Helayne Cortez - São Paulo
Repórter aparece em plano americano, com a expressão facial série. Ela não altera sua postura corporal durante a fala. A câmera permanece parada.

Tab.1. Fonte: Jornal do SBT Manhã. SBT. 21.05.10

Durante sua aparição, a repórter se encontra em plano americano (PA), o que sugere um lugar mais distanciado em relação ao espectador e evidencia o sujeito num determinando espaço simbólico, o lugar do acontecimento. A repórter Helayne Cortez é enquadrada do lado direito da tela, possibilitando ênfase no fato que ocorre em segundo plano: crianças brincam com a professora num pátio. O destaque verbal dado ao termo aqui, articulado à imagem de crianças brincando, indica o lugar de onde se reporta o fato (uma creche). Durante a passagem, a repórter olha para o espectador e mantém

um dos telejornais, totalizando 45 edições. Em 2012, para atualizar os resultados obtidos, foram observadas mais uma edição de cada um dos programas. O percurso metodológico desta análise parte de um estudo exploratório da primeira amostra, pelo qual buscou-se recorrências nos tipos de performances dos repórteres. Nessa fase inicial, foi possível identificar uma postura majoritária e uma segunda alternativa. Com base nesses resultados preliminares e no aprofundamento dos eixos teóricos da pesquisa, uma nova análise foi empreendida em amostras específicas, exemplares dessas recorrências, de modo a interpretar relações propostas entre os sujeitos comunicativos a partir das distintas performances acionadas pelo repórter. 
uma postura formal e distanciada, buscando valorizar mais o dito pelo texto verbal do que a interação com o interlocutor.

Nessa passagem, o credenciamento do enunciado se pauta pela não inclusão do repórter como personagem da ação narrada e ênfase à demonstração daquilo que é noticiado. É possível notar o esforço, do ponto de vista verbal e audiovisual, em colocálo no lugar daquele que presencia o fato como forma de tornar seu relato autêntico. Para validar os atos reportados e se engajar na cena no lugar de espectador de telejornal, o sujeito enunciatário é convocado a testemunhar, no sentido de ver, atestar, verificar, comprovar aquilo que é dito pela repórter.

A constituição do sujeito cúmplice também posiciona o enunciatário como testemunha do fato reportado, ou seja, identifica-se essa mesma preocupação em demonstrar, via imagem, áudio e depoimento de fontes, aquilo que é narrado, o diferencial, contudo, esta no modo como o repórter se insere na notícia e dialoga com o espectador. Recorre-se à ideia de cumplicidade, relacionada ao sentido de partilha, consentimento, cooperação, conivência, o que implica construção de sentido de interação com o interlocutor. A questão da certificação não se limita ao que é configurado enquanto comprovação do dito, depende da participação do repórter, que não atua mais como mero anunciador do fato, é sujeito da ação narrada. Para que haja reconhecimento por parte do espectador do telejornal, este é convocado a uma posição de partilha, de adesão tácita ao que vive o repórter no ato de sua enunciação, sendo alçado ao espaço-tempo do acontecimento pela identificação com essa persona, sujeito da ação reportada.

Além de testemunha do dito, o interlocutor é convidado a se posicionar como cúmplice daquilo que está sendo vivido pelo repórter no processo de transmissão direta do programa, o que constrói simbolicamente um mesmo aqui e agora para os sujeitos comunicativos. Veja-se uma passagem retirada da reportagem exibida pelo Jornal Nacional sobre o preparo das pessoas que trabalham como vigilantes de banco.

\begin{tabular}{|c|c|}
\hline $\begin{array}{c}\text { Ao mesmo tempo em que protege os clientes que } \\
\text { estão dentro das agências, o sistema de segurança } \\
\text { de muitos bancos acaba provocando, por vezes, } \\
\begin{array}{c}\text { constrangimentos, confusões e, às vezes, casos graves. } \\
\text { Crédito: José Roberto Burnier - São Paulo }\end{array}\end{array}$ & $\begin{array}{c}\text { Repórter aparece no canto direito da tela, PA, tendo } \\
\text { ao fundo uma porta giratória. }\end{array}$ \\
\hline A maioria dos bancos tem este tipo de porta. & Burnier aponta para a porta. \\
\hline $\begin{array}{c}\text { Neste portal, em cima, tem este sensor de metais, que } \\
\text { é regulável, ele pode ficar mais ou menos sensível. }\end{array}$ & $\begin{array}{c}\text { Gira seu corpo em direção à porta para indicar onde } \\
\text { fica o sensor. Câmera faz movimento travelling em } \\
\text { direção à porta. }\end{array}$ \\
\hline $\begin{array}{c}\text { Agora eu estou com meu celular e chaves no bolso e } \\
\text { esse microfone na mão. }\end{array}$ & $\begin{array}{c}\text { Com a mão direita segura no bolso e, depois, aponta } \\
\text { para o microfone. }\end{array}$ \\
\hline Vou tentar entrar. & O repórter dá as costas e tenta passar pela porta. \\
\hline
\end{tabular}




\begin{tabular}{|c|c|}
\hline Sobe som (ruído de apito). & $\begin{array}{l}\text { Travelling da câmera nos aproxima da ação do } \\
\text { repórter. }\end{array}$ \\
\hline Oh, já apitou e a porta travou & $\begin{array}{l}\text { Fala de costas para a câmera, que acompanha seu } \\
\text { movimento }\end{array}$ \\
\hline $\begin{array}{l}\text { Segurança: Boa tarde senhor. } \\
\text { Repórter: Boa tarde. } \\
\text { Segurança: Portanto algum metal? } \\
\text { Repórter: Tô com esse microfone, } \\
\text { também celular e chaves. } \\
\text { Segurança: Por favor, passe o volume } \\
\text { e retorne até à faixa amarela. } \\
\text { Repórter: } O K\end{array}$ & $\begin{array}{c}\text { Repórter permanece de costas. Vemos a imagem de } \\
\text { um segundo personagem (o segurança), que aparece } \\
\text { do outro lado da porta. }\end{array}$ \\
\hline Então eu volto aqui na faixa amarela. & $\begin{array}{l}\text { O repórter volta a olhar para o espectador e retorna até } \\
\text { a rua. Câmera faz um movimento vertical para focalizar } \\
\text { seus pés sobre a faixa e volta a enquadrá-lo em PA. }\end{array}$ \\
\hline $\begin{array}{l}\text { Evidentemente que se eu tentar entrar de novo com } \\
\text { esse microfone na mão, a porta vai travar. Então eu } \\
\text { vou deixar esse microfone aqui e vou tentar entrar. }\end{array}$ & $\begin{array}{c}\text { Repórter entrega o microfone para "alguém" } \\
\text { (não visualizado) e passa pela porta. Câmera o } \\
\text { acompanha e finaliza o plano sequência com sua } \\
\text { entrada no interior do local. }\end{array}$ \\
\hline
\end{tabular}

Tab.2. Fonte: Jornal Nacional. Rede Globo. 07.05.10.

Nessa passagem, o repórter se insere corporalmente no relato para representar uma situação cotidiana: o funcionamento das portas automáticas e a conduta dos seguranças dos estabelecimentos bancários. Ao interpretar o papel do cidadão cliente de banco, o repórter José Roberto Burnier contracena com um segundo personagem, o suposto segurança, encenando um diálogo ordinário. O espectador é levado a testemunhar a tentativa dessa persona, o cidadão-repórter, de passar pela porta giratória não apenas enquanto testemunha da ação, mas enquanto participante. Atua como um terceiro personagem, a quem o repórter confidencia suas ações. Burnier se movimenta, projeta-se em direção a câmera, dirigindo-se, a todo tempo, à figura de um sujeito cúmplice que atua tacitamente no discurso. Além desses três sujeitos, um quarto é inserido na cena, o cinegrafista, que acompanha os deslocamentos corporais feitos pelo repórter, aparece refletido na porta espelhada do suposto banco e interage com ele quando recebe seu microfone.

Esse tipo de performance não mais pretende demarcar a presença supostamente neutra do telejornal no local do acontecimento, mas a presença de uma persona que vive e interpreta o dito. Nesse caso, o sentido de fazer crer passa por um processo de corporificação do enunciado, o que nos diz sobre uma mudança do tipo de qualidade evocada para tornar crível o fato. A questão não passa exatamente pela configuração de um macrossujeito enunciador (o telejornal) que atua a partir da figura do repórter. A construção aqui é de um sujeito social corporificado pelo sujeito mediador (o repórter que também é cidadão cliente de banco). Ao viver um fato ordinário, busca-se ampliar o poder 
de certificação, movimento que vai repercutir na posição convocada para enunciatário, agora posto no lugar de cúmplice do sujeito falante, de interlocutor cooperante, quando é levado ao interior do discurso.

A passagem do Jornal Nacional também ilustra a construção simbólica do "lugar do acontecimento" através da encenação do repórter, uma vez que ele não se apresenta num lugar reconhecível (na porta de um estabelecimento bancário, por exemplo). A identificação de um local geográfico é borrada pelo enquadramento fechado da câmera que focaliza o mediador perante uma porta giratória qualquer. Ao mesmo tempo, pela encenação, evoca-se o tempo-espaço simbólico de uma situação ordinária (o passar pela porta de segurança). Ou seja, é pela performance do repórter que se virtualiza um espaço cotidiano reconhecível.

Diferentemente do tipo de performance interpretada pelo repórter ventríloquo, que interage com a audiência enquanto sujeito testemunha que observa a ação reportada, esse tipo de atuação faz do repórter uma persona que se coloca na história. Conforma-se, assim, o lugar do sujeito interlocutor cúmplice, posição que implica numa interação mais próxima com o repórter, quando este não apenas relata o que viu e ouviu, mas torna-se personagem da ação narrada.

Essas formas de performatização da notícia são concebidas enquanto estratégias de comunicabilidade do telejornal e apontam para a importância de pensar esse formato televisivo não apenas a partir das mensagens (do seu conteúdo), mas das interações pospostas com o espectador e a cultura. Como resultado do trabalho analítico empreendido, as posições assumidas pelos repórteres e construídas para espectadores podem ser sintetizadas da seguinte forma:

\begin{tabular}{|l|l|}
\hline \multicolumn{1}{|c|}{$\begin{array}{c}\text { Sujeito Enunciador } \\
\text { (Repórter) }\end{array}$} & $\begin{array}{c}\text { Sujeito Enunciatário } \\
\text { (Espectador Virtual) }\end{array}$ \\
\hline $\begin{array}{l}\text { Ventríloquo } \\
\text { Postura distanciada em relação ao fato e ao seu } \\
\text { interlocutor. Representação da figura neutra. } \\
\text { Ênfase na demonstração daquilo que é noticiado. }\end{array}$ & $\begin{array}{l}\text { Testemunha } \\
\text { Lugar de observador do fato de modo a } \\
\text { validá-lo enquanto acontecimento noticioso. }\end{array}$ \\
$\begin{array}{l}\text { Performance contida. Reduzidos movimentos } \\
\text { corporais, referência verbal ao acontecimento } \\
\text { em si. Enquadramento de câmera em plano } \\
\text { americano valoriza o local do acontecimento. não está implicado no discurso, } \\
\text { Atua como "não eu". }\end{array}$ & $\begin{array}{l}\text { Eendo colocado no lugar distanciado daquele } \\
\text { que presencia/testemunha o que é revelado } \\
\text { pelo repórter. }\end{array}$ \\
$\begin{array}{l}\text { Sujeito anunciador dos fatos. Autenticação } \\
\text { da cobertura se vale do apagamento da } \\
\text { representação pessoal do repórter, que atua } \\
\text { como figurativização do telejornal. }\end{array}$ & \\
\hline
\end{tabular}




\begin{tabular}{|l|l|}
\hline \multicolumn{1}{|c|}{$\begin{array}{c}\text { Sujeito Enunciador } \\
\text { (Repórter) }\end{array}$} & $\begin{array}{l}\text { Sujeito Enunciatário } \\
\text { (Espectador Virtual) }\end{array}$ \\
\hline $\begin{array}{l}\text { Persona } \\
\text { Postura próxima em relação ao interlocutor. } \\
\text { Repórter se inclui na ação narrada, torna-se } \\
\text { personagem do relato e dialoga de modo } \\
\text { explícito com o espectador. }\end{array}$ & $\begin{array}{l}\text { Cúmplice } \\
\text { Sujeito testemunha o fato narrado na } \\
\text { posição de cúmplice, o que implica maior } \\
\text { interação com o repórter e ação por este } \\
\text { relatada ou vivida. }\end{array}$ \\
$\begin{array}{l}\text { Figurativização do telejornal se confunde } \\
\text { com representação pessoal do repórter, que } \\
\text { corporifica um sujeito social. Repórter se } \\
\text { movimento, utiliza gestos e expressões faciais } \\
\text { variadas. Enquadramentos de câmera variados } \\
\text { acompanham a movimentação do corpo do } \\
\text { repórter. Atua como "eu". }\end{array}$ & $\begin{array}{l}\text { Enunciatário é convocado a partilhar a } \\
\text { ação vivida pelo repórter como interlocutor } \\
\text { cooperante alçado ao espaço-tempo do } \\
\text { acontecimento. É co-autor daquilo que está } \\
\text { sendo performatizado pelo mediador. }\end{array}$ \\
$\begin{array}{l}\text { Sujeito implicado na ação narrada. Sentido } \\
\text { de fazer crer se vale da performatização do } \\
\text { enunciado pelo corpo do mediador. }\end{array}$ & \\
\hline
\end{tabular}

Tab.3. Caracterização das posições construídas para os sujeitos comunicativos do telejornal.

\section{Dois planos de constatação analítica}

O corpo do repórter se impõe como um importante expediente de certificação dos relatos noticiosos na TV. Os resultados deste estudo revelam como marcas hegemonicamente reconhecidas como "do telejornal" são reiteradas e também reconfiguradas, produzindo novas performances e formas de interação com o consumidor de notícias. Em contraposição à construção do repórter como uma figura neutra e supostamente imparcial, que se esforça para distanciar-se da ação narrada e de seu interlocutor, a posição de persona indica uma nova forma de performatização da notícia televisiva.

No lugar de observador não implicado nos fatos, papel assumido até então como pressuposto de construção de credibilidade, o repórter passa a se construir enquanto ser social que vive os fatos e, por isso, é autorizado a discorrer sobre eles. Nesse caso, o sujeito narrador não é apenas repórter, aquele que nos conta sobre algo que ocorreu com terceiros, é também ator ao se incluir na ação reportada, o que sinaliza na direção de uma espécie de inversão poética para um mesmo efeito pretendido: autenticidade dos relatos. Esse movimento, que não parece se confundir com perda de autoridade, nos leva à crítica da forma hegemônica como o telejornalismo tem sido tratado em parte da literatura disponível no Brasil, responsável por reforçar dissonâncias entre discursos instituídos e práticas culturais.

As contribuições de Martín-Barbero se mostram fundamentais para o estudo no sentido de nos fazer perceber as formas do telejornal como lugares de mediação cultural, 
que atravessam os textos (os programas) e constituem marcas de gênero. Assim, ao dar ao corpo, à imagem, ao áudio, à transmissão direta uma dimensão de tecnicidade, entende-se que tais dispositivos expressivos não são simplesmente da ordem do instrumento, mas da constituição de práticas e modos de reconhecimento cultural. É essa convicção que nos permite dar conta de articulações entre inovações discursivas e transformações materiais características do telejornalismo contemporâneo.

A análise buscou evidenciar a produtividade, do ponto de vista metodológico, do diálogo proposto com o Mapa das Mediações e também com a pragmática, na tentativa de compreender o telejornalismo pelo viés comunicacional. Enquanto lugar configurador de comunicabilidade televisiva, o contexto comunicativo funcionou como um modo de operacionalizar, do ponto de vista analítico, relações entre lógicas de produção e de consumo no marco dos formatos industriais. Obviamente, o esforço aqui demonstrado aponta para o avanço do trabalho analítico no sentido de interpretar relações com matrizes culturais e contextos sociais que respingam nas configurações e reconfigurações das formas dos telejornais pensadas enquanto estratégias de comunicabilidade deste formato industrial.

Juliana Freire Gutmann é professora doutora do Programa de Pós-Graduação em Comunicação e Cultura Contemporâneas da UFBA.

jugutmann@gmail.com

\section{Referências}

BARBEIRO, H.; LIMA, P. R. Manual de telejornalismo: os segredos da notícia na TV. Rio de Janeiro: Campus, 2002.

BECKER, B. A linguagem do telejornal: um estudo da cobertura dos 500 anos do descobrimento do Brasil. Rio de Janeiro: Epapers, 2005.

CAMPELO, C. R. Cal(e)idoscorpos: um estudo semiótico do corpo e seus códigos. São Paulo: Annablume, 1996.

COUTINHO, Iluska. Dramaturgia no telejornalismo: a narrativa da informação em rede e nas emissoras de televisão de Juiz de Fora. Rio de Janeiro: Mauad, 2012.

ECO, U. Lector in Fabula. São Paulo: Perspectiva, 1986.

FECHINE, Y. Performance dos apresentadores do telejornal: a construção do ethos. Famecos. Porto Alegre, n.36, 2008.

GOMES, I. M. M. Gênero televisivo como categoria cultural: um lugar no centro do mapa das mediações de Jesús Martín-Barbero. Famecos. Porto Alegre, v.18, n.01, 2011.

GOULART, A. P. SACRAMENTO, I. Desafios para uma análise histórica do telejornalismo no Brasil. In: GOMES, I. M. M. (org.) Análise do telejornalismo: desafios teóricos-metodológicos. Salvador: Edufba, 2012. 
GUTMANN, J. F. Formas do telejornal: um estudo das articulações entre valores jornalísticos e linguagem televisiva. Tese (Doutorado). Universidade Federal da Bahia, Salvador, 2012.

HAGEN, S. A emoção como estratégia de fidelização da audiência: Jornal Nacional e os laços de afetividade com o telespectador. Verso e Reverso, São Leopoldo, 2008.

LEAL, B. S. Do texto ao discurso: as normas sem história dos manuais de telejornalismo. In: GOMES, I. M. M. (org.) Análise do Telejornalismo: desafios teóricos-metodológicos. Salvador: Edufba, 2012.

MACHADO, A. A televisão levada a sério. São Paulo: Editora Senac, 2001.

MARTÍN-BARBERO, J. Ofício de Cartógrafo: travessias latino-americanas da comunicação na cultura. São Paulo: Loyola, 2004.

Dos meios às mediações: comunicação, cultura e sociedade. 5. ed. Rio de Janeiro: Editora UFRJ, 2008.

RODRIGUES, A. D. As dimensões da pragmática na comunicação. Rio de Janeiro: Diadorim, 1995.

SILVA, F. M. Marcas do passado tecendo o presente: a formação histórica dos programas de entrevistas no Brasil. In: GOMES, I. M. M. (Org.). Análise de telejornalismo: desafios teórico-metodológicos. Salvador: Edufba, 2012.

VERON, E. Il est là, je lê vois, il me parle. Revue Communications, nº 38, Paris: Le Seuil, 1983.

ZUMTHOR, P. Performance, recepção e leitura. São Paulo: EDUC, 2000.

Artigo recebido em setembro e aprovado em novembro de 2013. 